\title{
Anti-oxidant and pro-oxidant effects on nerve conduction velocity, endoneurial blood flow and oxygen tension in non-diabetic and streptozotocin-diabetic rats
}

\author{
N.E.Cameron, M. A.Cotter, V.Archibald, K.C.Dines, E. K. Maxfield \\ Department of Biomedical Sciences, University of Aberdeen, Scotland, UK
}

Summary Increased oxygen free radical activity, coupled with reduced protection against oxidative stress, could play a role in the aetiology of neurovascular abnormalities in experimental diabetes mellitus. To test this hypothesis, non-diabetic and streptozotocindiabetic rats were treated with the anti-oxidant probucol or the pro-oxidant primaquine. One-month diabetes caused $21.4 \%$ and $13.6 \%$ reduction in sciatic motor and saphenous sensory conduction velocity $(p<0.001)$. These deficits were prevented by probucol treatment $(p<0.001)$. After 1-month untreated diabetes, conduction velocity deficits were reversed by a further month of probucol treatment $(p<0.001)$. For non-diabetic rats, primaquine treatment caused a $12.9 \%$ reduction in motor conduction velocity $(p<0.001)$, which was prevented by probucol treatment $(p<0.001)$. Primaquine treatment did not affect diabetic rats. Sciatic nerve nutritive endoneurial blood flow, measured using microelectrode polarography and hydrogen clearance, was $48.0 \%$ reduced by 2 -month diabetes $(p<0.001)$. This was completely prevented by probucol treatment $(p<0.001)$. Primaquine treatment did not affect blood flow in diabetic rats. However, in non-diabetic rats it caused a $30.0 \%$ reduction $(p<0.01)$ which was prevented by probucol treatment $(p<0.05)$. Sciatic endoneurial oxygen tensions were also measured by microelectrode polarography. Mean tension was $38.8 \%$ reduced by diabetes $(p<0.001)$. This was prevented by probucol treatment. Non-diabetic rats given primaquine treatment showed a $21.7 \%$ reduction in endoneurial oxygen tension $(p<0.01)$. The data suggest that vascular-mediated nerve dysfunction in diabetes depends on oxidative stress, and that similar effects in non-diabetic rats may be produced by pro-oxidant treatment. This provides evidence for the potentially important role of oxygen free radical activity in diabetic neuropathy. [Diabetologia (1994) 37:449-459]

Key words Neuropathy, nerve conduction, endoneurial blood flow, hypoxia, oxidative stress, probucol, antioxidant, pro-oxidant, vascular endothelium, angiotensin converting enzyme, diabetic rat.
Oxidative stress has been implicated in the aetiology of the complications [1,2] of diabetes mellitus. The body's natural anti-oxidant defence mechanisms [3-5] are compromised and diabetes may cause lowering of

Received: 13 September 1993 and in revised form: 19 November 1993

Corresponding author: Dr. N.E. Cameron, Department of Biomedical Sciences, University of Aberdeen, Marischal College, Aberdeen AB9 1 AS, Scotland, UK

Abbreviations: GSH, reduced glutathione; OFR, oxygen free radical; NCV, nerve conduction velocity; $\mathrm{ACE}$, angiotensin converting enzyme; EMG, electromyogram; NO, nitric oxide. tissue glutathione (GSH), superoxide dismutase, ascorbic acid, catalase and vitamin E levels. Recently, experiments have demonstrated that anti-oxidant treatment with butylated hydroxytoluene [6] or GSH [7] can prevent the development of nerve dysfunction in experimental diabetes. The mechanisms by which oxidative stress causes neurological changes in diabetes are not known in detail. Oxygen free radical (OFR) damage could affect neurons directly [8], however, effects could also be indirect, via deleterious changes in nerve vascular supply as endothelial function is particularly sensitive to OFRs in diabetic rats [9-11].

Some doubt has been cast over the ability of anti-oxidant treatment to reverse established NCV deficits in 
diabetic rats by GSH treatment [7]. However, the lack of success in that experiment could also be due to dose considerations or the nature of the anti-oxidant used. One aim of this investigation was to assess the effect of the OFR scavenger, probucol [12-14], in both preventing and reversing NCV deficits in streptozotocindiabetic rats.

If oxidative stress produces sufficiently powerful deleterious effects in diabetic rats to be a major cause of reduced $\mathrm{NCV}$, it follows that pro-oxidant treatment should produce a similar effect in non-diabetic rats. Thus, a second aim of the study was to examine whether chronic treatment with the anti-malarial drug, primaquine, whose quinoline-quinone intermediate metabolites are powerful oxidants [15], could cause NCV deficits.

A reduction in the nutritive component of sciatic endoneurial blood flow occurs within 1 week of induction of diabetes by streptozotocin [16]. Correction of this perfusion deficit by vasodilator treatment restores NCV [16-22]. As anti-oxidants and pro-oxidants have vascular effects [9-11], a major aim was to examine their actions on endoneurial blood flow in diabetic and non-diabetic rats. Deleterious nerve function changes do not directly depend on the blood flow reduction itself but on the consequent endoneurial hypoxia [23], therefore, endoneurial oxygen tensions were also measured.

\section{Materials and methods}

\section{Animals and diabetes induction}

Male Sprague-Dawley rats (Aberdeen University breeding colony), 19 weeks old at the start of the study were used. Nondiabetic animals acted as onset controls. Others were given streptozotocin (Sigma, Poole, Dorset, UK) at $40-45 \mathrm{mg} \cdot \mathrm{kg}^{-1}$ in $20 \mathrm{mmol} \cdot \mathrm{l}^{-1}$ sodium citrate buffer, pH 4.5, i.p. . Diabetes was verified $24 \mathrm{~h}$ later by estimating hyperglycaemia and glycosuria (Visidex II and Diastix; Ames, Slough, UK). Diabetic rats were tested weekly, and weighed daily. They were rejected if blood glucose concentration was less than $20 \mathrm{mmol} \cdot \mathrm{l}^{-1}$ or if they showed a consistent increase in body weight over 3 days. Mortality rates following diabetes induction were less than $10 \%$, and none of the treatments used affected this. Samples for plasma glucose measurement using a standard test kit (GOD-Perid method; Boehringer Mannheim, Mannheim, Germany) were taken from the tail vein or carotid artery on the day of final experiments. Plasma ACE concentrations were determined using a standard diagnostic test kit (Sigma).

Three studies were undertaken. In the first investigation on $\mathrm{NCV}$, diabetic rats were given probucol (Sigma) treatment, as a $1 \% \mathrm{w} / \mathrm{w}$ dietary supplement, from 3 days after induction in a preventive study over 1 month. The delay between induction and commencement of treatment was introduced to prevent probucol interfering with the actions of streptozotocin [6]. Pretreatment of animals with this dose of probucol was previously shown to protect aorta endothelium-dependent relaxation against the acute deleterious effects of elevated glucose concentration in vitro [11]. Another group of rats with 1-month untreated diabetes were also given probucol for a further month to examine whether NCV deficits could be reversed. One- and 2-month untreated diabetic control and non-diabetic control groups were also employed. Additional groups of diabetic and non-diabetic rats were treated for 1 month with primaquine (Sigma), given in the drinking water, the concentration being adjusted to take account of water consumption in the different groups, such that the daily dose was approximately $0.5 \mathrm{mg} \cdot \mathrm{kg}^{-1}$. Primaquine is an orally active anti-malarial agent and oxidant whose metabolic quinoline-quinone intermediates are electron-carrying redox compounds [15]. The dose of primaquine was chosen to be equivalent to that recommended for killing the malarial gametocytes in erythrocytes of patients.

The timecourse of reversal of motor NCV deficits and subsequent washout of drug effects was examined in a second investigation for a group of 7 diabetic rats given probucol treatment following 2-month untreated diabetes.

In the third investigation, final experiments examined sciatic endoneurial blood flow. The groups employed were nondiabetic and 2-month diabetic controls, non-diabetic and diabetic rats treated for 2 months with probucol, a non-diabetic group treated for 1 month with primaquine, and a further nondiabetic group given combined treatment with probucol and primaquine for 1 month. Further rats from diabetic and nondiabetic control, probucol-treated diabetic and primaquinetreated non-diabetic groups were also used to examine sciatic endoneurial oxygen tensions. For the probucol-treated and joint probucol-primaquine-treated non-diabetic groups further information was obtained about NCV changes. Motor NCV to tibialis anterior muscle was measured in the contralateral leg 3 days before blood flow recording.

\section{Acute measurements of nerve conduction velocity}

In final experiments (investigation 1), rats were anaesthetized with urethane (1-1.5 $\mathrm{g} \cdot \mathrm{kg}^{-1}$ i.p.). Methods have been described in detail previously $[24,25]$. Briefly, the sciatic nerve was exposed and bipolar stimulating electrodes were placed close to it at the sciatic notch and knee. A concentric bipolar electrode was inserted into either tibialis anterior (peroneal sciatic division) or gastrocnemius (tibial sciatic division) muscles to monitor evoked EMG activity. Potentials from each stimulating site were averaged eight times. NCVs for tibialis anterior and gastrocnemius were calculated by dividing the distance between stimulating electrodes by the average latency difference between the onset of EMG potentials evoked from the two sites. The results of the two motor nerve measurements were averaged and taken to represent sciatic motor NCV [16]. Nerve temperature was monitored using a thermocouple probe, and maintained in the range $36.5-37.5^{\circ} \mathrm{C}$ by radiant heat. Body temperature was also maintained around $37^{\circ} \mathrm{C}$ using radiant heat and monitored by a rectal probe. Sensory NCVs were also measured between groin and ankle for the saphenous nerve.

\section{Sciatic nerve polyol pathway metabolite and myo-inositol levels}

For a subset of groups from investigation 1, sciatic nerve samples were taken from the contralateral leg before rats were killed by exsanguination. They were frozen in liquid $\mathrm{N}_{2}$ and stored at $-80^{\circ} \mathrm{C}$ until subsequent analysis. Nerve sugars and polyols were determined by gas chromatography of trimethylsilyl derivatives prepared from aqueous deproteinized extracts [26]. 
Table 1. Body weights and plasma glucose levels in control, pro-oxidant-treated control, diabetic and anti-oxidant-treated diabetic rats

\begin{tabular}{|c|c|c|c|c|}
\hline \multirow[t]{2}{*}{ Group } & \multirow[t]{2}{*}{$n$} & \multicolumn{2}{|c|}{ Weight (g) } & \multirow{2}{*}{$\frac{\text { Plasma glucose }}{\left(\mathrm{mmol} \cdot \mathrm{l}^{-1}\right)}$} \\
\hline & & Start & End & \\
\hline Control & 10 & $467 \pm 9$ & & $10.6 \pm 1.2$ \\
\hline 1-month diabetic & 11 & $461 \pm 11$ & $357 \pm 13$ & $41.1 \pm 2.7$ \\
\hline 1-month diabetic + pro-oxidant & 10 & $484 \pm 8$ & $394 \pm 11$ & $43.7 \pm 4.4$ \\
\hline 1-month diabetic + preventive anti-oxidant & 8 & $478 \pm 7$ & $378 \pm 13$ & $47.7 \pm 3.5$ \\
\hline
\end{tabular}

Data are mean \pm SEM

\section{Measurements of sciatic peroneal nerve conduction velocity with recovery}

For further investigations on NCV in treated diabetic and control rats (investigations 2 and 3), under halothane anaesthesia (2-5\% in air), sterile bipolar needle stimulating electrodes were inserted through the skin to stimulate sciatic nerve at the sciatic notch and popliteal fossa as previously described [20]. A sterile concentric bipolar recording electrode was inserted into tibialis anterior muscle. Leg skin temperature was kept in the range 35$37^{\circ} \mathrm{C}$ by radiant heat. EMGs evoked from both stimulation sites were averaged eight times and latencies of the first inflections were measured. The sciatic nerve between the two stimulating electrodes takes a fairly straight course, and interelectrode distances were used to calculate conduction velocity. NCV values obtained by this method are in good agreement with those found in acute measurement [24].

\section{Endoneurial blood flow and oxygen tension measured by microelectrode polarography}

Rats were anaesthetized with inactin (50-100 $\mathrm{mg} \mathrm{kg}^{-1}$ i.p.). The trachea was cannulated for artificial ventilation and a carotid cannula was used to monitor mean systemic blood pressure. Core temperature of the animal was monitored and regulated between 37 and $38^{\circ} \mathrm{C}$, using a rectal probe and radiant heat. The skin around the sciatic nerve incision was sutured to a metal ring and used to form a pool that was filled with mineral oil at $37^{\circ} \mathrm{C}$ to a depth of at least $1 \mathrm{~cm}$ to minimise diffusion of gases directly to or from the nerve. Rats were given neuromuscular blockade using d-tubocurarine (Sigma, $2 \mathrm{mg} \cdot \mathrm{kg}^{-1}$ via the carotid cannula) and artificially ventilated. The level of anaesthesia was monitored by observing any reaction of blood pressure to manipulation, and supplementary inactin was given as necessary. Nerve blood flow was measured by microelectrode hydrogen polarography as previously described [16,23]. Briefly, a glass-insulated platinum microelectrode (tip diameter $2-8 \mu \mathrm{m}$ ) was inserted into the middle portion of the sciatic nerve, above its trifurcation, and polarized at $0.25 \mathrm{~V}$ with respect to a reference electrode inserted subcutaneously in the flank of the rat. $10 \% \mathrm{H}_{2}$ was added to the inspired gas, the proportions of $\mathrm{O}_{2}$ and $\mathrm{N}_{2}$ being adjusted to $20 \%$ and $70 \%$ respectively. When the $\mathrm{H}_{2}$ current recorded by the electrode had stabilized ( $15-40 \mathrm{~min}$ ), indicating equilibrium with arterial blood, the $\mathrm{H}_{2}$ supply was shut off and $\mathrm{N}_{2}$ delivery was increased appropriately. The $\mathrm{H}_{2}$ clearance curve was recorded until baseline $(20 \mathrm{~min}-1 \mathrm{~h})$. This procedure was then repeated at another electrode site. After the experiment, clearance curves were digitized and mono- or bi-exponential curves were fitted to the data by computer using appropriate software (Inplot, Graphpad, San Diego, Calif., USA). The slow exponent, representing nutritive flow $[27,28]$, was accepted. The average of the two determinations was taken to represent sciatic endoneurial blood flow. Vascular conductance was calculated by dividing blood flow by the average mean arterial blood pressure during the recording period.

Endoneurial oxygen tensions were measured using methods similar to those described in Tuck et al. [23] and Newrick et al. [29] with glass-insulated platinum microelectrodes (tip diameter $<2.5 \mu \mathrm{m}$ ) which had been coated with a semipermeable membrane by dipping in collodion dissolved in xylene [30]. Microelectrodes were polarized at $-0.75 \mathrm{~V}$ and linearity was assessed in saline at $37^{\circ} \mathrm{C}$ bubbled with $\mathrm{O}_{2}-\mathrm{N}_{2}$ mixtures from $2 \%$ to $20 \% \mathrm{O}_{2}$. They were inserted approximately $100 \mu \mathrm{m}$ into the endoneurium and oxygen tension readings were taken at $50 \mu \mathrm{m}$ depth increments over a further $500 \mu \mathrm{m}$. For the occasionally encountered nerves that remained as separate tibial and peroneal fascicles over the course of the sciatic nerve, the larger fascicle was used and the additional depth increment was restricted to $400 \mu \mathrm{m}$. This process was repeated at five different sites along the nerve, resulting in 45-55 tension measurements per nerve. The mineral oil pool covering the nerve was bubbled with $\mathrm{N}_{2}$ to reduce diffusion of atmospheric oxygen. The microelectrode currents were calibrated in saline bubbled with air $(21 \%$ oxygen) and in saturated sodium sulphite solution ( $0 \%$ oxygen) between penetrations. Results from a penetration were rejected if there was greater than $10 \%$ sensitivity drift between successive calibrations. The rats were artificially ventilated with air, or with oxygen-enriched air if $\mathrm{PaO}_{2}$ fell below $80 \mathrm{~mm} \mathrm{Hg}$ and could not be corrected by adjusting respiratory rate or depth. $\mathrm{PaO}_{2}$ was measured at the end of each microelectrode penetration (Model $238 \mathrm{pH} /$ blood gas analyser; Ciba-Corning, Halstead, Essex, UK).

\section{Statistical analysis}

Data are expressed as mean \pm SEM. One-way analysis of variance was performed, followed by Bonferroni-t-tests to correct for multiple comparisons and assign differences to individual groups where overall significance $(p<0.05)$ was attained. Paired Student's $t$-tests were used to assess the significance of within-rat changes in investigation 2 and unpaired Student's $t$-tests were used for comparison with a non-diabetic control group. 


\section{Results}

Investigation 1: effects of anti-oxidant and pro-oxidant treatments on sciatic motor and saphenous sensory conduction velocity

Body weights and plasma glucose levels are shown in Table 1 . One- and 2-month diabetes caused approximately $20-25 \%$ reductions in body weight, and hyper-
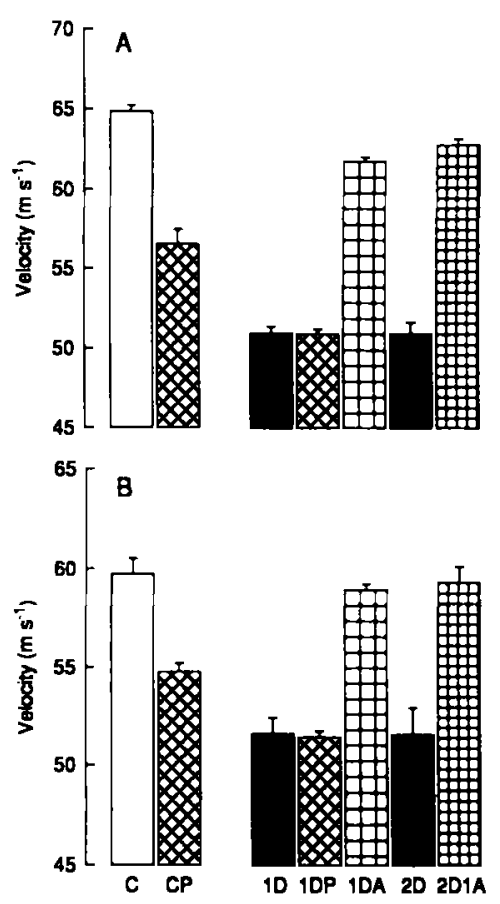

Fig. 1 A, B. Sciatic motor (A) and saphenous sensory (B) conduction velocity for non-diabetic and diabetic rats treated with the anti-oxidant probucol or the pro-oxidant primaquine. C, non-diabetic control group, $n=10$; $C P$, non-diabetic group treated for 1 month with the pro-oxidant primaquine, $n=10$; $1 \mathrm{D}, 1$-month diabetic control group, $n=11 ; 1 \mathrm{DP}, 1$-month diabetic group treated with primaquine, $n=9 ; 1 \mathrm{DA}, 1$-month diabetic group treated with the anti-oxidant probucol, $n=8 ; 2 \mathrm{D}$, 2-month diabetic control group, $n=14 ; 2 \mathrm{D} 1 \mathrm{~A}, 2$-month diabetic group untreated for the first month then treated for the second month with the anti-oxidant probucol, $n=10$. Data are group means \pm SEM. Statistical analysis - sciatic motor (A): C vs $\mathrm{CP}, 1 \mathrm{D}, 1 \mathrm{DP}$, or $2 \mathrm{D}, p<0.001 ; \mathrm{C}$ vs $1 \mathrm{DA}, p<0.05$; $\mathrm{C}$ vs $2 \mathrm{D} 1 \mathrm{~A}, \mathrm{NS} ; 1 \mathrm{DA}$ vs $1 \mathrm{D}, p<0.001 ; 1 \mathrm{DP}$ vs $1 \mathrm{D}, \mathrm{NS} ; 2 \mathrm{D} 1 \mathrm{~A}$ vs $2 \mathrm{D}$, $p<0.001$. Saphenous (B): C vs $1 \mathrm{D}, 1 \mathrm{DP}$, or $2 \mathrm{D}, p<0.001$; C vs $\mathrm{CP}, p<0.05 ; \mathrm{C}$ vs $1 \mathrm{DA}$ or $2 \mathrm{D} 1 \mathrm{~A}, \mathrm{NS} ; 1 \mathrm{DA}$ vs $1 \mathrm{D}, p<0.001$; $1 \mathrm{DP}$ vs $1 \mathrm{D}, \mathrm{NS} ; 2 \mathrm{D} 1 \mathrm{~A}$ vs $2 \mathrm{D}, p<0.001$
N. E. Cameron et al.: Anti- and pro-oxidant effects on nerve

glycaemia. Neither probucol nor primaquine treatment of diabetic rats had significant effects on body weights or plasma glucose concentrations compared to age-matched untreated diabetic groups. Similarly, treatment of non-diabetic rats had no effect on body weight.

NCV (Fig. 1) was affected by both treatments. Onemonth diabetes caused a $21.4 \%(p<0.001)$ reduction in sciatic motor NCV (Fig. 1 A), which remained close to this level (21.5\% reduction) after 2 months $(p<0.001)$. Primaquine treatment did not significantly affect motor NCV in diabetic rats. However, in nondiabetic rats it produced a $12.9 \%$ deficit $(p<0.001)$. Probucol treatment, in both preventive and reversal groups, resulted in motor NCVs that were increased compared to age-matched diabetic groups $(p<0.001)$. For the reversal group, NCV was not significantly different from non-diabetic controls, however, for the prevention group a similar $4.8 \%$ deficit remained which was marginally significant $(p<0.05)$.

Similar observations were made for sensory saphenous NCV (Fig. 1B). Thus, there were $13.6 \%$ and $13.7 \%$ NCV reductions after 1- and 2-month diabetes respectively $(p<0.001)$. Primaquine treatment was without significant effect for diabetic rats, but caused an $8.3 \% \mathrm{NCV}$ reduction in non-diabetic rats $(p<0.05)$. For both preventive and reversal probucol-treated diabetic groups NCV was within the non-diabetic range, significantly greater than for age-matched diabetic controls $(p<0.001)$.

Sciatic nerve polyols are shown in Table 2. Sorbitol and fructose concentrations were elevated approximately nine-fold and four-fold by diabetes and there was a $50 \%$ reduction in myo-inositol. These changes were not significantly affected by reversal probucol treatment of diabetic rats.

\section{Investigation 2: timecourse of reversal of motor conduction velocity deficits in diabetic rats by anti-oxidant treatment}

Following 2-month untreated diabetes, NCV to tibialis anterior muscle was reduced $(p<0.0001)$ by $16 \%$ compared to control values (Fig. 2). Upon instigation of a $1 \%$ probucol dietary supplement, NCV increased slowly and reached an asymptote at 14 days. The in-

Table 2. Sciatic nerve polyol pathway metabolites and myo-inositol concentrations

\begin{tabular}{lrlll}
\hline Group & $n$ & Sorbitol & Fructose & Myo-inositol \\
& & & & \\
\hline Control & 10 & $96.4 \pm 9.5$ & $390.6 \pm 32.8$ & \\
Diabetic & 11 & $1033.0 \pm 59.6^{\mathrm{a}}$ & $1804.9 \pm 90.9^{\mathrm{a}}$ & $568.3 \pm 44.4$ \\
Diabetic + reversal anti-oxidant & 9 & $798.7 \pm 49.4^{\mathrm{a}}$ & $1626.4 \pm 117.8^{\mathrm{a}}$ & $289.2 \pm 10.9^{\mathrm{a}}$ \\
\hline
\end{tabular}

Data are mean \pm SEM. They were subjected to log transformation prior to statistical evaluation as Bartlett's test for homogeneity of variance revealed that standard deviations were not equal.

a $p<0.001$ compared to control group 
Table 3. Body weights, plasma glucose concentrations and systemic arterial blood pressures for control, diabetic, and anti-oxidant and pro-oxidant treated control and diabetic groups used in endoneurial blood flow measurements

\begin{tabular}{|c|c|c|c|c|c|}
\hline \multirow[t]{2}{*}{ Group } & \multirow[t]{2}{*}{$n$} & \multicolumn{2}{|c|}{ Weight (g) } & \multirow{2}{*}{$\frac{\text { Plasma glucose }}{\left(\mathrm{mmol} \cdot \mathrm{I}^{-1}\right)}$} & \multirow{2}{*}{$\frac{\text { Systemic pressure }}{(\mathrm{mm} \mathrm{Hg})}$} \\
\hline & & Start & End & & \\
\hline Control & 10 & $498 \pm 8$ & & $6.7 \pm 0.4$ & $135.5 \pm 6.0$ \\
\hline $\begin{array}{l}\text { Control + anti-oxidant } \\
\text { Control + pro-oxidant } \\
\text { Control + anti-oxidant + pro-oxidant } \\
\text { Diabetic } \\
\text { Diabetic + anti-oxidant } \\
\text { Diabetic + pro-oxidant }\end{array}$ & $\begin{array}{r}8 \\
11 \\
9 \\
16 \\
9 \\
9\end{array}$ & $\begin{array}{l}464 \pm 7 \\
429 \pm 8 \\
453 \pm 7 \\
478 \pm 7 \\
459 \pm 7 \\
442 \pm 12\end{array}$ & $\begin{array}{l}478 \pm 8 \\
461 \pm 10 \\
472 \pm 7 \\
375 \pm 9 \\
345 \pm 18 \\
335 \pm 12\end{array}$ & $\begin{array}{l}8.3 \pm 0.6 \\
8.1 \pm 0.9 \\
7.6 \pm 0.6 \\
38.0 \pm 2.8 \\
39.6 \pm 2.9 \\
44.5 \pm 2.6\end{array}$ & $\begin{array}{l}139.4 \pm 5.7 \\
140.7 \pm 2.5 \\
126.2 \pm 7.5 \\
122.8 \pm 3.4 \\
122.9 \pm 4.1 \\
120.3 \pm 5.4\end{array}$ \\
\hline
\end{tabular}

Data are mean \pm SEM

Table 4. Sciatic motor conduction velocity to tibialis anterior muscle in control rats treated with anti-oxidant and with combined pro- and anti-oxidant treatment

\begin{tabular}{lcc}
\hline Group & $n$ & $\begin{array}{l}\text { Conduction velocity } \\
\left(\mathrm{m} \cdot \mathrm{s}^{-1}\right)\end{array}$ \\
\hline $\begin{array}{l}\text { Control } \\
\begin{array}{l}\text { Control }+ \\
\text { anti-oxidant }\end{array}\end{array}$ & 10 & $61.25 \pm 0.49$ \\
$\begin{array}{l}\text { Control + } \\
\text { pro-oxidant } \\
\begin{array}{l}\text { Control + anti-oxidant }+ \\
\text { pro-oxidant }\end{array}\end{array}$ & 8 & $61.77 \pm 0.33$ \\
\hline
\end{tabular}

Data are mean \pm SEM.

${ }^{a} p<0.001$, compared to control group;

${ }^{\mathrm{b}} p<0.001$, effect of anti-oxidant treatment compared to control + pro-oxidant group

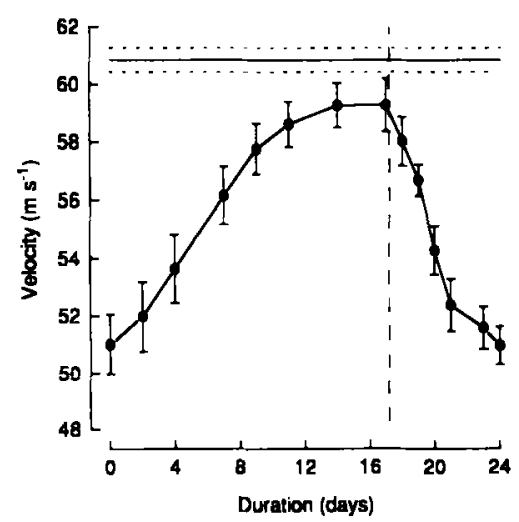

Fig. 2. Timecourse of reversal of sciatic motor conduction velocity in fibres supplying tibialis anterior muscle by probucol treatment after 2 months of untreated diabetes. Serial conduction velocity measurements on a group of 2 -month diabetic rats $(n=7)$ before (day 0$)$ and during treatment. Conduction velocity was followed to asymptote and then treatment was discontinued (vertical dashed line). Conduction velocity was monitored during probucol washout until it returned to baseline. Data points are means \pm SEM. The continuous horizontal line flanked by dashed lines represents the mean \pm SEM for conduction velocity in group of non-diabetic rats $(n=10)$ measured using the same method crease in NCV was significant from 2 days $(p=0.02)$ onwards. Asymptote values (days 14 and 17) were not significantly different from non-diabetic controls. When treatment was stopped, NCV gradually decreased over 4-6 days back to the pretreatment level. The decline, relative to asymptote, was significant after 2 days $(p=0.016)$. After 4 days washout (day 21), NCV was not significantly different from the baseline value.

\section{Investigation 3: effects of anti-oxidant and pro-oxidant treatments on sciatic endoneurial blood flow and oxygen tension in diabetic and non-diabetic rats}

Body weights and plasma glucose levels for the groups used in blood flow determinations are given in Table 3, and show the pattern of weight loss and hyperglycaemia characterised in the first investigation. Table 3 also includes blood pressure measurements made during the hydrogen clearance experiments. Analysis of variance revealed that there were significant variations in blood pressure $(p<0.02)$. Mean values showed a $13 \%$ range, however, post hoc between group comparisons using the Bonferroni test did not reveal any significant differences.

Endoneurial blood flow (Fig. 3A) was reduced by $48.0 \%$ after 2 -month diabetes $(p<0.001)$. This was completely prevented by probucol treatment $(p<$ 0.001 ). Probucol had no significant effect on blood flow in non-diabetic rats. Primaquine-treatment had no significant effect on blood flow in diabetic rats. However, for primaquine-treated non-diabetic rats, endoneurial blood flow was reduced by $30.0 \%(p<0.01)$. For a group of non-diabetic rats that had combined probucol and primaquine treatments, endoneurial blood flow was in the non-diabetic range, significantly greater than for primaquine treatment alone $(p<0.05)$.

Endoneurial vascular conductance (Fig. $3 \mathrm{~B}$ ) was reduced by $43.2 \%$ in the diabetic control group $(p<$ 0.001 ). With probucol, conductance was in the nondiabetic range for diabetic rats, and was unaffected by treatment for non-diabetic rats. While primaquine treatment did not significantly affect diabetic rats, it caused a $32.1 \%$ decrease in conductance in non- 
diabetic rats $(p<0.001)$. Probucol treatment prevented the primaquine-induced decrease in conductance in non-diabetic rats $(p<0.01)$.

To provide further information about motor NCV in sciatic fibres supplying tibialis anterior muscle, these were measured in the contralateral nerves 3 days before blood flow determination for the non-diabetic

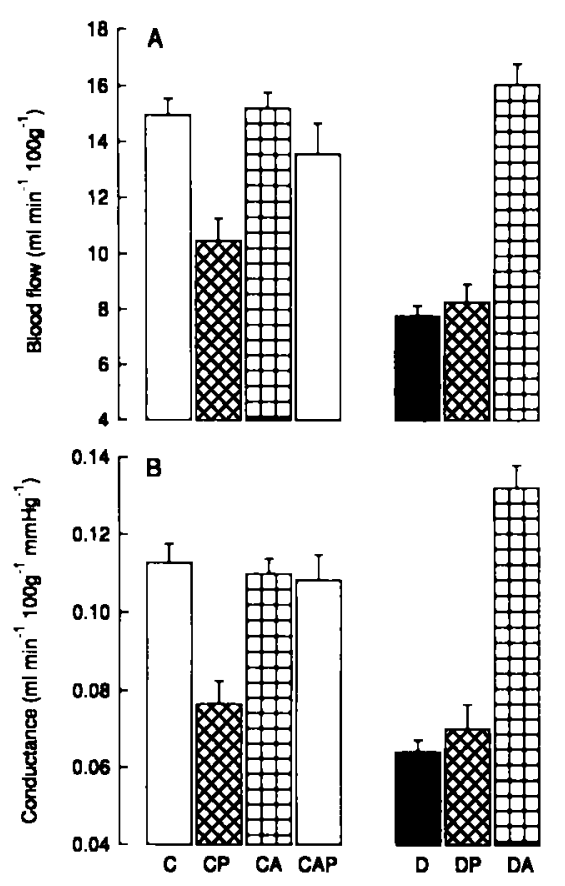

Fig. 3A, B. Sciatic nutritive endoneurial blood flow (A) and vascular conductance (B) measured by microelectrode polarography and hydrogen clearance for non-diabetic and diabetic rats treated with the anti-oxidant probucol or the pro-oxidant primaquine. C, non-diabetic control group, $n=10$; $\mathrm{CP}$, nondiabetic group treated for 1 month with the pro-oxidant primaquine, $n=11 ; \mathrm{CA}$, non-diabetic group treated for 1 month with the anti-oxidant probucol, $n=8$; CAP, non-diabetic group treated for 1 month with both probucol and primaquine, $n=9$; D, 2-month diabetic control group, $n=16$; DP, 1 -month diabetic group treated with the pro-oxidant primaquine, $n=9$; DA, 2 month diabetic group treated with the anti-oxidant probucol, $n=9$. Data are group means \pm SEM. Statistical analysis - blood flow (A): C vs CP, $p<0.01$; C vs CA or CAP, NS; CAP vs CP, $p<0.05 ; \mathrm{C} v$ v D or DP, $p<0.001$; D vs DA, $p<0.001$; D vs DP, NS. Vascular conductance (B): $\mathrm{C}$ vs $\mathrm{CP}, p<0.01$; $\mathrm{C}$ vs $\mathrm{CA}$ or $\mathrm{CAP}$, NS; CAP vs CP, $p<0.01$; C vs D or DP, $p<0.001$; $\mathrm{D}$ vs DA, $p<0.001 ; \mathrm{D}$ vs DP, NS groups treated with probucol, or a combination of primaquine and probucol. Results are given in Table 4, along with non-diabetic control values estimated by the same method. Also included for comparison are data from tibialis anterior NCV obtained in investigation 1 for primaquine-treated control rats. Probucol treatment did not significantly affect NCV compared to control values. However, probucol prevented any reduction in NCV resulting from primaquine treatment $(p<0.001)$.

Endoneurial oxygen tension histograms were measured in a subset of the treatment groups, and body weights, plasma glucose concentrations, systemic arterial blood pressures and arterial and nerve mean oxygen tensions are given in Table 5. Compared to non-diabetic controls (Fig. 4A), primaquine treatment of non-diabetic rats (Fig. 4B) resulted in a shift of oxygen tension towards hypoxia. Thus, $82.5 \pm 5.2 \%$ of oxygen tension measurements were more than $25 \mathrm{~mm}$ $\mathrm{Hg}$ in control rats, whereas with primaquine treatment this fell to $55.8 \pm 7.4 \%(p<0.05)$. Mean oxygen tensions were $21.7 \%(p<0.01)$ reduced by primaquine (Table 5). There was a characteristic shift in the oxygen tension distribution towards hypoxia with untreated diabetes (Fig. 4C). Thus, despite no significant differences in arterial oxygen tensions or mean systemic arterial pressure (Table 5), mean endoneurial oxygen tension was $38.8 \%(p<0.001)$ reduced by diabetes and only $28.9 \pm 4.7 \%$ of tension measurements were more than $25 \mathrm{~mm} \mathrm{Hg}(p<0.01$ vs the non-diabetic control group). With probucol treatment of diabetic rats (Fig.4D), the oxygen tension distribution was normal, as was mean oxygen tension (Table 5), and $80.0 \pm 7.2 \%$ of tensions were more than $25 \mathrm{~mm} \mathrm{Hg}(p<0.01$ vs the diabetic group).

\section{Haematocrits and plasma ACE levels}

The haematocrits for rats from investigations 1 and 3 are given in Table 6. One-way analysis of variance revealed that there were significant variations in haematocrit $(p<0.001)$. When individual betweengroup comparisons were made using the Bonferroni test, there were no significant effects of primaquine

Table 5. Body weights, plasma glucose concentrations and systemic arterial blood pressures and oxygen tensions for control, diabetic, and anti-oxidant treated diabetic and pro-oxidant treated control and groups used in endoneurial oxygen tension measurements

\begin{tabular}{|c|c|c|c|c|c|c|c|}
\hline \multirow[t]{2}{*}{ Group } & \multirow[t]{2}{*}{$n$} & \multicolumn{2}{|c|}{ Weight (g) } & \multirow{2}{*}{$\frac{\text { Plasma glucose }}{\left(\mathrm{mmol} \cdot \mathrm{l}^{-1}\right)}$} & \multirow{2}{*}{$\frac{\text { Systemic pressure }}{(\mathrm{mm} \mathrm{Hg})}$} & \multirow{2}{*}{$\frac{\mathrm{PaO}_{2}}{(\mathrm{~mm} \mathrm{Hg})}$} & \multirow{2}{*}{$\frac{\mathrm{PnO}_{2}}{(\mathrm{~mm} \mathrm{Hg})}$} \\
\hline & & Start & End & & & & \\
\hline$\overline{\text { Control }}$ & 13 & $478 \pm 13$ & & $10.2 \pm 0.8$ & $139.5 \pm 4.7$ & $94.9 \pm 2.6$ & $33.9 \pm 1.4$ \\
\hline Control + pro-oxidant & 11 & $460 \pm 8$ & $481 \pm 8$ & $8.3 \pm 0.6$ & $126.3 \pm 4.8$ & $94.2 \pm 2.1$ & $26.6 \pm 1.9^{a}$ \\
\hline Diabetic & 12 & $470 \pm 7$ & $333 \pm 13$ & $42.4 \pm 1.8$ & $125.5 \pm 1.7$ & $94.5 \pm 2.3$ & $20.7 \pm 1.1^{\mathrm{b}}$ \\
\hline Diabetic + anti-oxidant & 9 & $459 \pm 9$ & $358 \pm 10$ & $42.1 \pm 1.9$ & $127.9 \pm 2.7$ & $97.9 \pm 3.4$ & $32.9 \pm 1.6^{c}$ \\
\hline
\end{tabular}

Data are mean \pm SEM. $\mathrm{PaO}_{2}$, arterial oxygen tension; $\mathrm{PnO}_{2}$, sciatic nerve mean endoneurial oxygen tension.

${ }^{\mathrm{a}} p<0.01,{ }^{\mathrm{b}} p<0.001$, compared to control group;

${ }^{c} p<0.001$, effect of treatment compared to diabetic group 


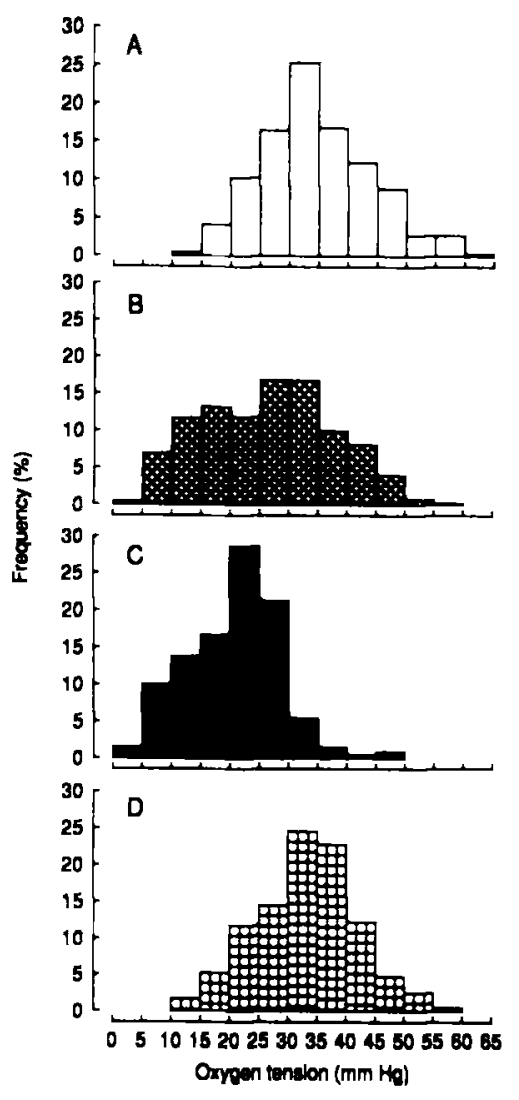

Fig. 4A-D. Sciatic endoneurial oxygen tension distributions for non-diabetic and diabetic rats treated with the anti-oxidant probucol or the pro-oxidant primaquine. A, non-diabetic control group, $n=13 ; \mathbf{B}$, non-diabetic group treated with the prooxidant primaquine, $n=11$; C, 2-month diabetic group, $n=12$; D, 2-month diabetic group treated with the anti-oxidant probucol, $n=9.5 \mathrm{~mm} \mathrm{Hg}$ bin size

Table 6. Haematocrits for groups used in investigations 1 and 3

\begin{tabular}{lrl}
\hline Group & $n$ & Haematocrit (\%) \\
\hline Control & 11 & $47.54 \pm 1.04$ \\
Control + pro-oxidant & 31 & $47.24 \pm 0.76$ \\
Control + anti-oxidant & 8 & $48.75 \pm 1.49$ \\
Control + anti-oxidant + & 9 & $50.61 \pm 0.92$ \\
pro-oxidant & & \\
Diabetic & 19 & $43.68 \pm 0.67$ \\
Diabetic + pro-oxidant & 14 & $43.71 \pm 0.68$ \\
Diabetic + anti-oxidant & 17 & $47.53 \pm 0.74^{\mathrm{a}}$ \\
\hline
\end{tabular}

Data are mean \pm SEM.

${ }^{a} p<0.05$, effect of treatment compared to diabetic group

treatment on control or diabetic rats. There was a tendency for haematocrit to be lower with diabetes, however, this was not statistically significant compared to the non-diabetic control group. There was also a tendency for haematocrit to be higher with probucol treatment, however, this was not statistically significant except for the comparison involving diabetic groups $(p<0.05)$.

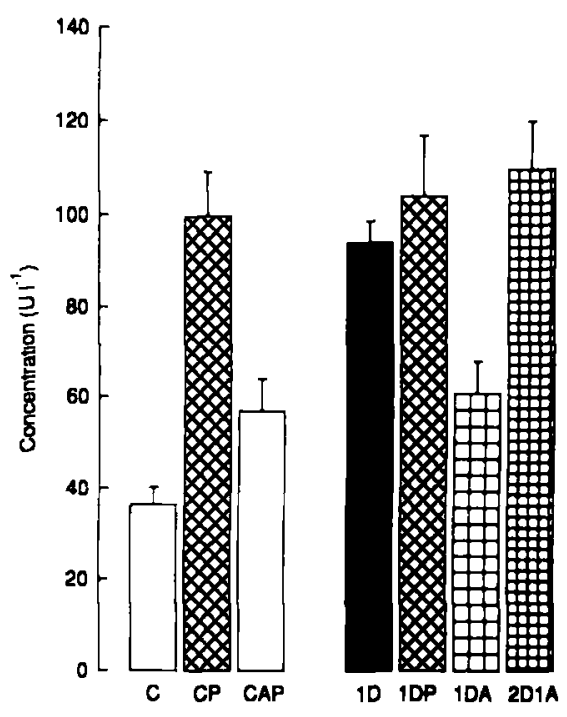

Fig.5. Plasma angiotensin converting enzyme concentrations in non-diabetic and diabetic rats treated with the anti-oxidant probucol or the pro-oxidant primaquine. C, non-diabetic control group, $n=19$; CP, non-diabetic group treated for 1 month with the pro-oxidant primaquine, $n=11$; CAP, non-diabetic group treated for 1 month with primaquine and probucol, $n=9 ; 1 \mathrm{D}, 1$ month diabetic control group, $n=11 ; 1 \mathrm{DP}, 1$-month diabetic group treated with primaquine, $n=10 ; 1 \mathrm{DA}, 1$-month diabetic group treated with the anti-oxidant probucol, $n=11 ; 2 \mathrm{D} 1 \mathrm{~A}, 2$ month diabetic group untreated for the first month then treated for the second month with the anti-oxidant probucol, $n=10$. Data are group means $\pm S E M$. Statistical analysis $-C$ vs $C P, 1 D$, $1 \mathrm{DP}$ or $2 \mathrm{D} 1 \mathrm{~A}, p<0.001$; C vs CAP or $1 \mathrm{DA}, \mathrm{NS}$; CAP vs CP, $p<0.01 ; 1 \mathrm{D}$ vs $1 \mathrm{DA}, p<0.05 ; 1 \mathrm{D}$ vs $2 \mathrm{D} 1 \mathrm{~A}$, NS

Plasma ACE concentrations are shown in Figure 5. Compared to the control group, ACE was 2.6-fold greater with 1 -month diabetes $(p<0.001)$. A similar 2.7-fold increase was noted for the primaquine-treated control group $(p<0.001)$. Anti-oxidant treatment with probucol largely prevented the increase in ACE concentration as a result of both diabetes $(p<0.05)$ and primaquine treatment $(p<0.01)$. However, 1 -month reversal probucol treatment after 1 -month untreated diabetes did not restore plasma ACE levels. Primaquine treatment of diabetic rats for one month did not significantly affect ACE concentration.

\section{Discussion}

The results clearly show that anti-oxidant treatment can prevent and reverse motor and sensory NCV deficits in diabetic rats, without affecting nerve polyol pathway metabolites or myo-inositol. The data agree with previous preventive studies using butylated hydroxytoluene [6] and GSH [7]. However, twice weekly GSH injections were unable to reverse an established reduction in motor and sensory NCV [7] whereas, in this study, probucol achieved reversal within 2 weeks of the start of treatment. The apparent discrepancy between these studies may simply result from a non-optimal 
dose regimen for GSH, which is rapidly metabolized and, therefore, is unlikely to have given enough protection against oxidative stress on days when the rats were not treated. Alternatively, the nature of the anti-oxidant may be more relevant. Both butylated hydroxytoluene and probucol are highly lipid soluble whereas GSH is water soluble. Thus, if the relevant OFR-mediated damage is to the lipid component of cell membranes or to LDL (which, when oxidised, becomes cytotoxic $[31,32])$ then lipid soluble anti-oxidants are likely to afford a high degree of protection.

The notion that oxidative stress could be an important cause of NCV deficits is further supported by the effect of primaquine on NCV in non-diabetic rats. With the dose employed, the effect was less than for untreated diabetes, however, in both cases NCV deficits were prevented by probucol treatment. Primaquine did not worsen NCV in diabetic rats, although agents that interfere with vascular endothelium function, the cyclooxygenase inhibitor flurbiprofen [33] and the NO synthase inhibitor $\mathrm{N}^{\mathrm{G}}$-nitro-L-arginine [34], can further reduce NCV. This could suggest that the level of oxidative stress conferred by the dose of primaquine was less than that produced by diabetes itself, therefore, little further change would be expected. This argument is consistent with the relative magnitudes of NCV deficits for primaquine-treated non-diabetic and untreated diabetic groups.

Endoneurial nutritive blood flow was reduced by diabetes, in agreement with several other studies using hydrogen clearance techniques $[16,21,23]$. Primaquine treatment of non-diabetic rats also reduced blood flow. These changes resulted from neurovascular alterations as conductance was similarly influenced. In both cases, anti-oxidant treatment protected against the development of blood flow and vascular conductance deficits. Probucol did not influence blood flow in non-diabetic rats. This argues against an effect similar to conventional vasodilators, which improve $\mathrm{NCV}$ in diabetes, acting on vascular smooth muscle by diverse mechanisms $[16-19,22,35]$. OFRs have a vascular action by reacting with NO to produce peroxynitrite which can decay to nitrogen dioxide and hydroxyl radical $[36,37]$. This impairs endothelium-dependent relaxation [9, 36], and hydroxyl radical may cause cell damage [37]. Probucol can give protection. In diabetic rat aorta, in vitro, and for acute exposure of aortas from nondiabetic rabbits to high glucose concentrations, impaired endothelium-dependent relaxation was associated with increased OFR production. It was prevented by free radical scavengers either in the tissue bath [10, 38], or by pre-treatment of the animals [11]. It is likely that primaquine treatment mimicked this facet of diabetes- or hyperglycaemia-induced vascular dysfunction as it was antagonised by probucol. When variations in flow due to differences in blood pressure are eliminated by expressing the data as vascular conductance, the probucol-treated diabetic group appeared to have higher values than controls. This was not statistically significant using the conservative Bonferroni test, however, it was significant $(p<0.05)$ on the less conservative Student-Newman-Keuls test and may represent a real finding. Interestingly, in vitro experiments on aorta from diabetic rats revealed greater spontaneous NO release than from control aorta in the presence of exogenous superoxide dismutase, suggesting upregulation of NO production masked by elevated OFR production [38]. It is possible that enhanced vasa nervorum conductance in anti-oxidant treated diabetic rats reflects a similar mechanism.

Other treatments, which do not affect blood flow in non-diabetic rats, notably aminoguanidine $[21,39]$ and aldose reductase inhibitors $[22,40,41]$, nevertheless improve both nerve perfusion and NCV in diabetes. While their mechanisms of action may differ from that of probucol, they could also include effects related to prevention of oxidative stress. Thus, aminoguanidine can prevent the formation of advanced glycation endproducts that can quench NO [42]. However, it also prevents the oxidation of LDL [43] and, therefore, may protect vascular endothelium from direct cytotoxic effects [31, 32, 44]. Aldose reductase inhibitors are "NADPH-sparing" and elevated levels of this cosubstrate for NO synthase would allow greater local vasodilator production [45]. However, this effect would also elevate GSH levels [46] with a consequent upregulation of superoxide dismutase [3], thus, promoting enhanced protection against oxidative stress. Interestingly, both anti-oxidants and aldose reductase inhibitors prevent diabetes- or glucose-induced OFR-related reductions in endothelium-dependent relaxation $[11,45$, 47-49]. Thus, directly or indirectly, aminoguanidine and aldose reductase inhibitors probably have anti-oxidant-like actions relevant for their effects on diabetic nerve dysfunction.

One potential cause of primaquine's action that can be ruled out for this investigation is haemolysis of erythrocytes, which would increase blood viscosity and could potentially impair blood flow. Erythrocyte haemolysis can be a side effect of treatment in susceptible patients with congenital glucose 6-phosphate dehydrogenase deficiency. In this condition there is a deficit in NADPH production by the hexose monophosphate shunt. The consequent decrease in GSH concentration increases erythrocyte susceptibility to oxidative stress by primaquine, resulting in haemolysis [15]. Diabetes has a similar effect on NADPH and GSH levels because of polyol pathway activity [45], therefore, it was important to monitor haematocrit in the primaquine-treated diabetic groups. However, the data show that this potential haemolytic action did not occur with the dose of primaquine used.

Plasma ACE levels are increased in diabetic rats and patients [50]. The reason is not known, although it may reflect endothelial damage [51]. Diabetes and primaquine treatment resulted in comparable increases in 
ACE, indicating similarities in vascular dysfunction in the two models. Probucol prevented ACE elevation in both cases, suggesting OFR involvement. Agents that block the renin-angiotensin system (ACE inhibitors and angiotensin II receptor antagonists) prevent and correct NCV deficits in diabetic rats $[18,52-54]$ and early clinical trials show evidence of beneficial effects in patients [55]. It could be argued that oxidative stress exerts an indirect effect on nerve function via changes in ACE levels. Thus, the protective action of probucol could depend upon prevention of OFR-dependent ACE increases. However, probucol reversed NCV deficits after 1-month diabetes, whereas it did not reverse the ACE increase. Therefore, the primary action of anti-oxidants is probably separate and depends on acute vascular consequences. The swift reversal of $\mathrm{NCV}$ deficits and their return when treatment ceased argues for a rapid effect such as prevention of OFRmediated NO destruction [36].

Endoneurial oxygen tension measurements revealed a shift towards hypoxia with untreated diabetes. The data are in close quantitative agreement with the original demonstration of this phenomenon [23]. Primaquine treatment of non-diabetic rats also shifted oxygen tension distribution towards hypoxia, although the effect was less marked than for diabetes. There was good agreement between the relative magnitudes for reductions in motor NCV $(60 \%)$, blood flow (63\%) and mean endoneurial oxygen tension (56\%) caused by primaquine treatment compared to diabetes. This supports a mechanistic link between nerve perfusion, oxygenation and function. The reduction in mean tension with diabetes was approximately $80 \%$ as large as the reduction in nutritive blood flow. A similar difference was also apparent in the original study [23]. The reason probably concerns metabolic changes in diabetic nerves. Exposure to chronic hypoxia, and under some conditions acute hyperglycaemia, causes an adaptation towards greater reliance on anaerobic metabolism for energy supply [56-58], the functional correlate being increased resistance to ischaemic conduction failure. Endoneurial oxygen tension depends on the balance of supply and demand. Although supply (nutritive flow) is reduced, metabolic adaptation also reduces demand. Thus, although clearly hypoxic, oxygen tensions are higher than expected from simple consideration of the blood flow deficit alone. The oxygen tension distribution within nerves from diabetic rats was greatly improved with probucol treatment. In a previous study, the anti-oxidant, butylated hydroxytoluene, partially prevented the development of resistance to hypoxic conduction failure [6]. This probably occurred because nerve fibres had reduced hypoxia exposure and, therefore, showed correspondingly less metabolic adaptation.

In conclusion, oxidative stress in experimental diabetes or because of pro-oxidant treatment causes neurovascular defects, resulting in endoneurial hypo- xia that impairs nerve function. Anti-oxidant protection is reduced in diabetic patients and markers of oxidative stress are increased. OFRs can damage neurons directly as well as indirectly via their vascular supply. Although it is not known whether anti-oxidants can be used to correct a chronic disease state, it is plausible that treatment could have potential therapeutic value in diabetic neuropathy.

Acknowledgements. NEC is supported by a Wellcome Trust Research Leave Fellowship. VA, KCD and EKM are supported by research studentships from the British Heart Foundation, Scotia and Zeneca Pharmaceuticals, respectively.

\section{References}

1. Baynes JW (1991) Role of oxidative stress in the development of complications in diabetes. Diabetes 40: 405-412

2. Lyons TJ (1991) Oxidised low density lipoproteins - a role in the pathogenesis of atherosclerosis in diabetes. Diabetic Med 8: 411-419

3. Loven DH, Schedl H, Wilson Het al. (1986) Effects of insulin and oral glutathione on glutathione levels and superoxide dismutase activities in organs of rats with streptozotocin-induced diabetes. Diabetes 35: 503-507

4. Wohaieb SA, Godin DV (1987) Alterations in free radical tissue-defense mechanisms in streptozotocin-induced diabetes in rats. Effects of insulin treatment. Diabetes 36: 1014-1018

5. Karpen CW, Pritchard KA, Arnold JH, Cornwell DG, Pangonamala RV (1982) Restoration of the prostacyclin/thromboxane $A_{2}$ balance in the diabetic rat: influence of vitamin E. Diabetes 31: 947-951

6. Cameron NE, Cotter MA, Maxfield EK (1993) Antioxidant treatment prevents the development of peripheral nerve dysfunction in streptozotocin-diabetic rats. Diabetologia 36: 299-304

7. Bravenboer B, Kapelle AC, Hamers FPT, van Buren T, Erkelens DW, Gispen WH (1992) Potential use of glutathione for the prevention and treatment of diabetic neuropathy in the streptozotocin-induced diabetic rat. Diabetologia 35: 813-817

8. Low PA, Nickander KK (1991) Oxygen free radical effects in sciatic nerve in experimental diabetes. Diabetes 40: 873-877

9. Pieper GM, Gross GJ (1988) Oxygen free radicals abolish endothelium-dependent relaxation in diabetic rat aorta. Am J Physiol 255: H825-H833

10. Hattori Y, Kawasaki H, Kazuhiro A, Kanno M (1991) Superoxide dismutase recovers altered endothelium-dependent relaxation in diabetic rat aorta. Am J Physiol 261: H1086H1094

11. Tesfamariam B, Cohen RA (1992) Free radicals mediate endothelial cell dysfunction caused by elevated glucose. Am J Physiol 263: H321-H326

12. Bridges AB, Scott NA, Belch JJF (1991) Probucol, a superoxide free radical scavenger in vitro. Atherosclerosis 89: 263265

13. Buckley MMT, Goa KL, Price AH, Brogden RN (1989) Probucol: a reappraisal of its pharmacological properties and therapeutic use in hypercholesterolemia. Drugs 37: 761-800

14. Carew TE, Schwenke DC, Steinberg D (1987) Anti-atherogenic effect of probucol unrelated to its hypercholesterolemic effect: evidence that antioxidants in vivo can selectively inhibit low density lipoprotein degradation in macro- 
phage-rich fatty streaks and slow the progression of atherosclerosis in Wantanabe heritable hyperlipidemic rabbit. Proc Natl Acad Sci USA 84: 7725-7729

15. Goldsmith RS (1989) Antiprotozoal drugs. In: Katzung BG (ed) Basic and clinical pharmacology, 4 edn. Appleton and Lange, San Mateo, pp 645-665

16. Cameron NE, Cotter MA, Low PA (1991) Nerve blood flow in early experimental diabetes in rats: relation to conduction deficits. Am J Physiol 261: E1-E8

17. Cameron NE, Cotter MA, Ferguson $K$, Robertson S, Radcliffe MA (1991) Effects of chronic $\alpha$-adrenergic receptor blockade on peripheral nerve conduction, hypoxic resistance, polyols, $\mathrm{Na}^{+}-\mathrm{K}^{+}$-ATPase activity, and vascular supply in STZ-D rats. Diabetes 40: 1652-1658

18. Cameron NE, Cotter MA, Robertson S (1992) Angiotensin converting enzyme inhibition prevents the development of muscle and nerve dysfunction and stimulates angiogenesis in streptozotocin-diabetic rats. Diabetologia 35: 12-18

19. Hotta N, Kakuta H, Fukasawa H et al. (1992) Effect of niceritol on streptozocin-induced diabetic neuropathy in rats. Diabetes 41: 587-591

20. Cameron NE, Cotter MA, Robertson S, Maxfield EK (1993) Nerve function in experimental diabetes in rats: effects of electrical stimulation. Am J Physiol 264: E161-E166

21. Kihara M, Schmelzer JD, Poduslo JF, Curran FF, Nickander KK, Low PA (1991) Aminoguanidine effect on nerve blood flow, vascular permeability, electrophysiology, and oxygen free radicals. Proc Natl Acad Sci USA 88: 6107-6111

22. Yasuda H, Sonobe M, Yamashita M et al. (1989) Effect of prostaglandin $\mathrm{E}_{1}$ analogue TFC 612 on diabetic neuropathy in streptozocin-induced diabetic rats comparison with aldose reductase inhibitor ONO 2235. Diabetes 38: 832-838

23. Tuck RR, Schmelzer JD, Low PA (1984) Endoneurial blood flow and oxygen tension in the sciatic nerves of rats with experimental diabetic neuropathy. Brain 107: 935-950

24. Cameron NE, Cotter MA, Robertson S (1989) The effect of aldose reductase inhibition on the pattern of nerve conduction deficits in diabetic rats. Q J Exp Physiol 74: 917-926

25. Cameron NE, Cotter MA, Robertson S (1991) Essential fatty acid diet supplementation: effects on peripheral nerve and skeletal muscle function and capillarization in streptozocin-induced diabetic rats. Diabetes 40: 532-539

26. Stribling D, Mirrlees DJ, Harrison HE, Earl DCN (1985) Properties of ICI 128,436, a novel aldose reductase inhibitor and its effects on diabetic complications in the rat. Metabolism 34: 336-344

27. Day TJ, Lagerlund TD, Low PA (1989) Analysis of $\mathrm{H}_{2}$ clearance curves used to measure blood flow in rat sciatic nerve. $J$ Physiol 414: 35--54

28. Low PA, Lagerlund TD, McManis PG (1989) Nerve blood flow and oxygen delivery in normal, diabetic and ischemic neuropathy. Int Rev Neurobiol 31: $355-438$

29. Newrick PG, Wilson AJ, Jakubowski J, Boulton AJM, Ward JD (1986) Sural nerve oxygen tension in diabetes. BMJ 293: 1053-1054

30. Silver IA (1967) Polarography and its biological applications. Phys Med Biol 12: 285-299

31. Morel DW, Chisolm G (1989) Antioxidant treatment of diabetic rats inhibits lipoprotein oxidation and cytotoxicity. $\mathrm{J}$ Lipid Res 30: 1827-1834

32. Evensen SA, Galdal KS, Nilsen E (1983) LDL-induced cytotoxicity and its inhibition by anti-oxidant treatment in cultured human endothelial cells and fibroblasts. Atherosclerosis 49: 23-30

33. Cameron NE, Cotter MA, Dines KC, Robertson S, Cox D (1993) The effects of evening primrose oil on peripheral nerve function and capillarization in streptozotocin-diabetic rats: modulation by the cyclo-oxygenase inhibitor flurbiprofen. Br J Pharmacol 109: 972-979

34. Cameron NE, Cotter MA, Dines KC, Maxfield EK (1993) Pharmacological manipulation of vascular endothelium in non-diabetic and streptozotocin-diabetic rats: effects on nerve conduction, hypoxic resistance and endoneurial capillarization. Diabetologia 36: 516-522

35. Robertson S, Cameron NE, Cotter MA (1992) The effect of the calcium antagonist nifedipine on peripheral nerve function in streptozotocin-diabetic rats. Diabetologia 35: 11131117

36. Gryglewski RJ, Palmer RMJ, Moncado S (1986) Superoxide anion is involved in the breakdown of endothelium-derived vascular relaxing factor. Nature 320: $454-456$

37. Beckman JS, Beckman TW, Chen J, Marshall PA, Freeman BA (1990) Apparent hydroxyl radical production by peroxynitrite: implications for endothelial injury from nitric oxide and superoxide. Proc Natl Acad Sci USA 87: 16201624

38. Langenstroer P, Pieper GM (1992) Regulation of spontaneous EDRF release in diabetic rat aorta by oxygen free radicals. Am J Physiol 263: H257-H265

39. Cameron NE, Cotter MA, Dines K, Love A (1992) Effects of aminoguanidine on peripheral nerve function and polyol pathway metabolites in streptozotocin-diabetic rats. Diabetologia 35: 946-950

40. Hotta N, Kakuta H, Koh N et al. (1992) Effect of a new potent aldose reductase inhibitor, "TAT" on diabetic neuropathy of rats. Diabetologia 35 [Suppl 1]: A151 (Abstract)

41. Cameron NE, Cotter MA, Dines KC, Maxfield EK (1993) Effects of aldose reductase inhibition on nerve blood flow and oxygen tension in diabetic rats. Diabetologia 36 [Suppl 1]: A199 (Abstract)

42. Bucala R, Tracey KJ, Cerami A (1991) Advanced glycosylation products quench nitric oxide and mediate defective endothelium-dependent vasodilation in experimental diabetes. J Clin Invest 87: 432-438

43. Picard S, Parthasarathy S, Fruebis J, Witztum JL (1992) Aminoguanidine inhibits oxidative modification of low density lipoprotein protein and the subsequent increase in uptake by the macrophage scavenger receptor. Proc Natl Acad Sci USA 89: 6876-6880

44. Andrews HE, Brukdorfer KR, Dunn RC, Jacobs M (1987) Low-density lipoproteins inhibit endothelium-dependent relaxation in rabbit aorta. Nature 327: 237-239

45. Cameron NE, Cotter MA (1992) Impaired contraction and relaxation in aorta from streptozotocin-diabetic rats: role of polyol pathway activity. Diabetologia 35: 1011-1019

46. Dvornik D (1987) Hyperglycemia in the pathogenesis of diabetic complications. In: Porte D (ed) Aldose reductase inhibition. An approach to the prevention of diabetic complications. Biomedical Information Corporation, New York, pp 69-151

47. Tesfamariam B, Brown ML, Cohen RA (1992) Aldose reductase and myo-inositol in endothelial cell dysfunction caused by elevated glucose. J Pharmacol Exp Ther 263: 153-157

48. Tesfamariam B, Palacino JJ, Weisbrod RM, Cohen RA (1993) Aldose reductase inhibition restores endothelial cell function in diabetic rabbit aorta. J Cardiovasc Pharmacol 21: 205-211

49. Pieper GM, Mei DA, Langenstroer P, O'Rourke ST (1992) Bioassay of endothelium-derived relaxing factor in diabetic rat aorta. Am J Physiol 263: H676-H680

50. Tomlinson KC, Gardiner SM, Hebden RA, Bennett T (1992) Functional consequences of streptozotocin-induced diabetes mellitus, with particular reference to the cardiovascular system. Pharmacol Rev 44: 103-150 
51. Hallab M, Bled F, Ebran JM et al. (1992) Elevated serum angiotensin I converting enzyme activity in type 1 , insulin-dependent diabetic subjects with persistent microalbuminuria. Acta Diabetol 29: 82-85

52. Cameron NE, Cotter MA, Robertson S (1993) Rapid reversal of a motor nerve conduction deficit in streptozotocindiabetic rats by the angiotensin converting enzyme inhibitor lisinopril. Acta Diabetol 30: 46-48

53. Maxfield EK, Cameron NE, Cotter MA, Dines KC (1993) Angiotensin II receptor blockade improves nerve function, modulates nerve blood flow and stimulates endoneurial angiogenesis in streptozotocin-diabetic rats. Diabetologia 36: 1230-1237

54. Cameron NE, Love A, Maxfield EK, Cotter MA (1993) Vasodilator treatment improves sciatic endoneurial microenvironment and prevents the impaired regenerative response following nerve injury in diabetic rats. Diabetic Med 10 [Suppl 3]: A23 (Abstract)

55. Reja A, Tesfaye S, Harris N, Ward JD (1993) Improvement in nerve conduction and quantitative sensory tests following treatment with lisinopril. Diabetic Med 10 [Suppl 3]: A24 (Abstract)

56. Low PA, Schmelzer JD, Ward KK, Yao JK (1986) Experimental chronic hypoxic neuropathy: relevance to diabetic neuropathy. Am J Physiol 250: E94-E99

57. Low PA, Ward K, Schmelzer JD, Brimijoin S (1985) Ischemic conduction failure and energy metabolism in experimental diabetic neuropathy. Am J Physiol 248: E457-E462

58. Strupp M, Jund R, Schneider U, Grafe P (1991) Glucose availability and sensitivity to anoxia of isolated rat peroneal nerve. Am J Physiol 261: E389-E394 